Article

\title{
Usage Behaviour of Public Spaces Associated with Sport and Recreational Activities
}

\author{
Fátima Chacón-Borrego ${ }^{1, *}{ }^{\mathbb{D}}$, Juan Antonio Corral-Pernía ${ }^{1}$, Asunción Martínez-Martínez ${ }^{2}$ and \\ Carolina Castañeda-Vázquez ${ }^{1}$ (D) \\ 1 Department of Physical Education and Sports, Faculty of Education, University of Sevilla, 41013 Sevilla, \\ Spain; juancorral@us.es (J.A.C.-P.); carolinacv@us.es (C.C.-V.) \\ 2 Department of Research Methods and Diagnosis in Education, Faculty of Education, University of Granada, \\ 18071 Granada, Spain; asuncionmm@ugr.es \\ * Correspondence: fchacon@us.es; Tel.: +34-955-420-458
}

Received: 4 May 2018; Accepted: 6 July 2018; Published: 9 July 2018

\begin{abstract}
Public spaces (PS) encourage personal interaction and promote behaviours such as doing sport and recreational activities. This study analysed the characteristics of sport and recreational activities among the adult population of Seville associated with and/or determining the use of a PS for the activity. We adopted a cross sectional survey design with 1002 subjects (18+) from the municipality of Seville using a questionnaire on habits of sport and recreational activities. We then performed a descriptive, correlational and binary logistical regression analysis of the data. Results showed that the characteristics of sport and recreational activities associated with and determining the use of PS are age and gender as sociodemographic variables and the type of activity performed, high frequency and duration, on any day of the week and throughout the year.
\end{abstract}

Keywords: urban spaces; urban environment; habits; exercise; adults

\section{Introduction}

Apart from permitting the transit and mobility of the general public, urban public spaces also facilitate interactions between people, giving rise to specific actions and behaviours such as sport and taking exercise [1]. Rather than an isolated physical-material manifestation, as Castells [2] pointed out these urban and public spaces (PS) are a social expression. In this sense, this urban area constitutes a social disposition allowing subjects to make use of and appropriate (choices) these places. This is similar to what Bordieu referred to as Habitus (dispositions), forming the basis for the configuration of the lifestyles of individuals [3,4].

For that reason, the availability of appropriate and nearby physical spaces constitutes an important motivational element for the development and upkeep of active lifestyles [4], while their absence represents a serious obstacle for this same objective $[5,6]$. This raises important issues regarding the design and management of these spaces and policies towards health, sport and recreation because it means considering aspects beyond merely architectural criteria, including important factors such as social inclusion and the promotion of active lifestyles [4].

However, recent years have seen the design and implementation of community policies appropriating and using these PS with healthy behaviours and aimed at maintaining active lifestyles. Thus, in many cities (especially in Latin America) recreational bike-ways have been introduced. These are free community programs which temporarily close streets to all motorized traffic, allowing only pedestrians, runners, skaters and cyclists [7].

In many towns across Spain there are now what are known as biohealth circuits, which are essentially green spaces with equipment for people to exercise on. This represents a new philosophy 
towards the use of PS, aimed at promoting the healthy use of leisure time [6]. Similarly, parks and squares are a key element for doing sport and recreational activities in public spaces [8], in the same way that safe, transitable and aesthetically agreeable neighbourhoods have a positive influence on how much sport and recreational activities their inhabitants do [9].

Linked to the above, recent years have seen a growing trend in the use of PS for sport and recreational activities and this has been documented in several studies, both internationally and within Spain at national, regional and local levels [10]. Data from the latest Eurobarometer, conducted by the European Commission [11], shows that Europeans who do exercise, sport or some physical activity in general, perform these activities mainly in informal settings such as parks and outdoor public spaces $(40 \%)$. According to data from this study, Spain has one of the highest percentages $(53 \%)$ of people who do sport and recreational activities in a park or outdoors. In Spain, according to the last survey on Sporting habits in Spain conducted by the Ministry of Education, Culture and Sport in 2015 (MECYD) [12], most Spaniards (69.9\%) who did sport and recreational activities in 2014, did so in public outdoor spaces (park, country) as opposed to public and/or private facilities. Similarly, in the autonomous region of Andalusia, the rate of sport and recreational activities in public places increased from 32.4\% in 2007 to 36.5\% in 2012 [13] according to the Observatory of Sport in Andalusia (ODA). Previous data from that same project indicated that $50.8 \%$ of Seville's population did sport and recreational activities regularly, with PS being used most often for their activity (51.1\%) ahead of other spaces or facilities [14].

However, some studies have highlighted differences both in the profiles of users of these spaces and the characteristics and types of sport and exercise performed there. Previous studies on the use of PS for exercise, have recorded differences both in age [12-18] and, to a lesser extent due to the scarcity of studies, variables affecting the activity, such as type, frequency or intensity $[11,13,18,19]$.

The influence of these variables, both sociodemographic and characteristics of the sport and recreational activities, on the use of PS has received little analysis. However, this information would be extremely valuable to adapt policy on the design, creation and use of public spaces to meet the characteristics and needs of the people that use them, enabling them to appropriate these spaces and use them to forge a more active lifestyle.

On the basis of the data analysed, this study sets out to identify the characteristics (type of sport and recreational activities, frequency, duration, time of year and day of week) of the sports activity of Seville's adult population and the sociodemographic variables (age and gender), associated with the use of PS for said activity. It also aims to establish, if possible, the extent to which these variables determine the main use of these places for exercise.

\section{Materials and Methods}

This study adopted a non-experimental and cross-sectional survey design.

\subsection{Participants}

The sample consisted of 1002 subjects from the municipality of Seville, aged $\geq 18$ years. For the selection of the sample, we drew up a random and stratified sample in different districts of the city and then selected subjects using quotas of age $(n=12518$ to $24 ; n=40825$ to $44 ; n=29545$ to 64; and $n=174$ over 64$)$ and gender ( $n=471$ men and $n=531$ women). Subjects were selected using crossed quotas for municipal districts, gender and age. Passers-by were stopped in the street and asked if they would participate.

The level of reliability was established at $95.5 \%$ with an estimated error for the whole sample of $\pm 3.01 \%$.

Of the 1002 people interviewed, 50.8\% (509 subjects) stated that they had done sport and recreational activities in the previous year. The age quota distribution of the 509 subjects was as follows: 83 people aged 18-24 (21.12 \pm 2.06$), 204$ aged 25-44 (32.99 \pm 5.88$), 155$ aged $45-64$ (54.51 \pm 5.90$)$ and 67 people over $65(72.67 \pm 5.38)$. 


\subsection{Measuring Instruments}

We used the Questionnaire on habits of sport and recreational activities [20] with an $\alpha=0.84$. This questionnaire is based on the COMPASS project (Coordinated Monitoring of Participation in Sports in Europe) [21]. This study is based on the concept of sport as proposed by the Council of Europe's Sports Charter (1992):

"Sport means all forms of physical activity which, through casual or organized participation, aim at expressing or improving physical fitness and mental well-being, forming social relationships or obtaining results in competition at all levels" (art. 2a).

The variables analysed in the study were: use of public spaces (parks, street, beach, mountain or others) for regular sport and recreational activities, a variable in this dichotomic case (yes/no). Sociodemographic variables: gender, age interval. Characteristic variables of the sport and recreational activities: type of sport and recreational activities performed most during the previous year, frequency (less than once a month, between once a month and once a week, twice a week, more than twice a week) and duration (5-15, 15-30, 30-45, 45-60 min, more than $1 \mathrm{~h}$ ). It also collected information about when this activity was normally performed during the course of the year (holiday, non-holiday period or indifferent) and on which days of the week (weekdays, weekends or indifferent).

\subsection{Procedure}

We collected data by conducting face-to-face interviews in the street. The field work was conducted by the specialist company Nexo SCA, after training the interviewers.

Interviewers were provided with guidelines and exclusion criteria included not interviewing people near sports centres, schools or health centres, while the inclusion criteria were that they had to be a resident in the district in question and be 18 or over. The supervision and control of the field work was done by coordinating the interviewers and verifying compliance with the street route. The interviews lasted an average of $M=20.78 \mathrm{~min}(S D=5.6)$. After data collection, $14.9 \%$ of the interviews were verified by telephone.

\subsection{Statistical Analysis}

We conducted a descriptive analysis of frequencies and percentages, applying the Chi-square inferential test to check for relations between the nominal and ordinal variables. Spearman's Rho non-parametric test was used for the correlational analysis. The correlational level was established keeping to the published recommendations [22]. In turn, we used a binary logistic regression analysis to determine the variables explaining the use of public spaces for sport and recreational activities. We also calculated the level of association between the activity in these public spaces and the different, previously-mentioned variables (gender, age, frequency, duration, period of year and day of the week). In this case, we used the Odds Ratio (OR) and its 95\% confidence interval as a result. For all the tests, the level of significance was $p \leq 0.05$.

The coding of variables was "practice of sport and recreational activities in PS" (yes = 1; no =0); "gender" (man $=1$; woman $=0$ ). Data was processed using SPSS ${ }^{\circledR}$ version 22.0 (IBM Corp, Armonk, NY, USA) for Windows.

\section{Results}

Table 1 reveal that men use PS more than women to do sport and recreational activities, $59.2 \%$ to $42.1 \%$. As for the age intervals, we found that the use of these spaces increases with age, with the older population using it more, with percentages of $60 \%$ in the $45-64$ year age group and a similar percentage in those over $64(56.7 \%)$. 
Table 1. Sport and recreational activities practice in PS according to gender and age interval.

\begin{tabular}{cccccccc}
\hline \multirow{2}{*}{ Use of PS } & $\begin{array}{c}\text { Sport and Recreational Activities } \\
\text { Practice in the Last Year }\end{array}$ & \multicolumn{2}{c}{ Gender } & \multicolumn{4}{c}{ Age Interval } \\
\cline { 2 - 8 } & & Woman & Man & $\mathbf{1 8 - 2 4}$ & $\mathbf{2 5 - 4 4}$ & $\mathbf{4 5 - 6 4}$ & Over 64 \\
\hline \multirow{2}{*}{ Yes } & 260 & 102 & 158 & 28 & 101 & 93 & 38 \\
& $51.1 \%$ & $42.1 \%$ & $59.2 \%$ & $33.7 \%$ & $49.5 \%$ & $60 \%$ & $56.7 \%$ \\
\hline \multirow{2}{*}{ No } & 249 & 140 & 109 & 55 & 103 & 62 & 29 \\
& $48.9 \%$ & $57.9 \%$ & $40.8 \%$ & $66.3 \%$ & $50.5 \%$ & $40 \%$ & $43.3 \%$ \\
\hline \multirow{2}{*}{ Total } & 509 & 242 & 267 & 83 & 204 & 155 & 67 \\
& $100 \%$ & $100 \%$ & $100 \%$ & $100 \%$ & $100 \%$ & $100 \%$ & $100 \%$ \\
\hline
\end{tabular}

As shown in Table 2, the type of sport and recreational activities practiced most by the adult population in public places was that of walking $(40 \%)$, followed by cycling, running (percentages around $15 \%$ ) and football (7.7\%). A third level of activity included aerobics and keep-fit classes, as well as body building and toning. All the other physical activities performed in these places represented percentages $\leq 1 \%$ (Tai chi-yoga, rowing, roller-skating).

Table 2. Types of sport and recreational activities performed most in public spaces.

\begin{tabular}{cccc}
\hline Activities & Frequency/Percentage & Yes & No \\
\hline \multirow{2}{*}{ Walking (more than 10 min) } & $\mathrm{N}$ & 104 & 12 \\
& $\%$ & 40.0 & 4.8 \\
\hline \multirow{2}{*}{ Cycling } & $\mathrm{N}$ & 43 & 8 \\
& $\%$ & 16.5 & 3.2 \\
\hline \multirow{2}{*}{ Running } & $\mathrm{N}$ & 41 & 8 \\
& $\%$ & 15.7 & 3.2 \\
\hline \multirow{2}{*}{ Football } & $\mathrm{N}$ & 20 & 26 \\
& $\%$ & 7.7 & 10.4 \\
\hline \multirow{2}{*}{ Body building and toning } & $\mathrm{N}$ & 9 & 27 \\
& $\%$ & 3.5 & 10.8 \\
\hline \multirow{2}{*}{ Aerobics and keep-fit class } & $\mathrm{N}$ & 7 & 44 \\
& $\%$ & 2.7 & 17.7 \\
\hline
\end{tabular}

Results showed that people do sport and recreational activities in PS often, more than twice a week for $66.2 \%$ of the sample and for a long time, as $42.3 \%$ responded that they performed their sporting activities for more than one hour (Table 3).

Table 3. Frequency and duration of sport and recreational activities in public spaces.

\begin{tabular}{cccccccccc}
\hline & \multicolumn{4}{c}{ Frequency } & \multicolumn{4}{c}{ Duration } \\
\hline & $<$ Once/month & $\begin{array}{c}\text { Once/month } \\
\text { to once/week }\end{array}$ & Twice/week & $>$ twice/week & $5-15$ min & $15-30$ min & $30-45$ min & $45-60$ min & $+1 \mathrm{~h}$ \\
$\%$ & 4.2 & 15.4 & 14.2 & 66.2 & 1.2 & 12.3 & 15.4 & 28.8 & 42.3 \\
\hline
\end{tabular}

As for when people did the activity during the week, 54.6\% did so from Monday to Friday, while $37.7 \%$ did so on any day of the week and $7.7 \%$ only did the activity at weekends. For $82.7 \%$ it made no difference whether they were on holiday or not, while $13.1 \%$ only did the activity when they were not on holiday, while for $4.2 \%$ the opposite was the case (Table 4 ). 
Table 4. Sport and recreational activities practice in PS: days of the week and time of year.

\begin{tabular}{ccccccccc}
\hline $\begin{array}{c}\text { Moment of } \\
\text { Sport Practice }\end{array}$ & \multicolumn{4}{c}{ Days of the Week } & \multicolumn{5}{c}{ Time of Year } \\
\hline Answer & Weekdays & Weekends & Indifferent & Total & Non-holiday & Holiday & Indifferent & Total \\
\hline \multirow{2}{*}{ Yes } & 98 & 20 & 142 & 260 & 34 & 11 & 215 & 260 \\
& $37.7 \%$ & $7.7 \%$ & $54.6 \%$ & $100 \%$ & $13.1 \%$ & $4.2 \%$ & $82.7 \%$ & $100 \%$ \\
\hline \multirow{2}{*}{ No } & 163 & 14 & 72 & 249 & 107 & 7 & 135 & 249 \\
& $65.5 \%$ & $5.6 \%$ & $28.9 \%$ & $100 \%$ & $43 \%$ & $2.8 \%$ & $54.2 \%$ & $100 \%$ \\
\hline
\end{tabular}

Table 5 shows that the practice of sport and recreational activities in public spaces correlates positively and significantly with the variables of gender and age interval $(r=0.170$ and $r=0.159$; $p<0.01$ respectively). The size of the correlation increased between the place they performed the activity and the variables of days on which they did it $(r=0.279, p<0.01)$ and the time of year $(r=0.321$; $p<0.01$ ). There was also a low magnitude but significant, negative correlation between doing the sport and recreational activities and its duration $(r=-0.136 ; p<0.01)$. However, there was no correlation with the frequency.

Table 5. Correlations between variables of characteristics of sport and recreational activities performed in public spaces.

\begin{tabular}{cccccccc}
\hline Variables & & Gender & Age Interval & Frequency & Duration & Day of Week & Time of Year \\
\hline Sport and recreational & Coef. & $0.170^{* *}$ & $0.159^{* *}$ & -0.060 & $-0.136^{* *}$ & $0.279^{* *}$ & $0.321^{* *}$ \\
activities in PS & $P$ & 0.000 & 0.000 & 0.175 & 0.002 & 0.000 & 0.000 \\
\hline \multicolumn{7}{c}{ Note 1: Coef. Spearman's Rho. ${ }^{* *} p<0.01$}
\end{tabular}

As Table 6 shows, the binary logistic regression analysis which aimed to predict the use of PS for sport and recreational activities through the different characteristics of these activities, found that $24.3 \%$ of the variation in the use of PS for sport and recreational activities was explained by the type of activity, its frequency, days of the week on which it was done, the time of year, duration of the activity, as well as gender and age interval.

In turn, the duration of the sport and recreational activities, the type of activity and the time of year when it was done had significant associations $(p<0.01)$ with the use of PS, with an odd ratio $(\mathrm{OR})$ of $0.658,0.947$ and 1.711 respectively.

Likewise, there were also significant associations $(p<0.05)$ with frequency $(\mathrm{OR}=0.682)$, the days of the week on which the activity was performed $(\mathrm{OR}=1.503)$, gender $(\mathrm{OR}=1.773)$ and age interval $(\mathrm{OR}=1.411)$.

Table 6. Binary logistic regression analysis explaining the variance existing in the adult population of Seville who do sport and recreational activities in public spaces.

\begin{tabular}{|c|c|c|c|c|c|}
\hline \multicolumn{6}{|c|}{ Model $(-2$ Log Likelihood $=563.854 ;$ Cox \& Snell R Square $=0.243 ;$ Nagelkerke R Square $=0.324)$} \\
\hline Variables & Coefficient & Est. Error & Wald Statistic & OR $(95 \% \mathrm{CI})$ & $p^{\dagger}$ \\
\hline Type of activity & -0.055 & 0.010 & 31.395 & $0.947(0.929-0.965)$ & 0.000 \\
\hline Frequency & -0.382 & 0.135 & 7.989 & $0.682(0.523-0.889)$ & 0.005 \\
\hline Day of week for doing activity & 0.407 & 0.122 & 11.160 & $1.503(1.183-1.909)$ & 0.001 \\
\hline Time of year for doing activity & 0.537 & 0.133 & 16.310 & $1.711(1.318-2.220)$ & 0.000 \\
\hline Duration & -0.419 & 0.117 & 12.874 & $0.658(0.524-0.827)$ & 0.000 \\
\hline Gender & 0.572 & 0.225 & 6.499 & $1.773(1.141-2.753)$ & 0.011 \\
\hline Age interval & 0.344 & 0.119 & 8.393 & $1.411(1.118-1.781)$ & 0.004 \\
\hline Constant & 0.816 & 0.780 & 1.094 & 2.261 & 0.296 \\
\hline
\end{tabular}

Note: OR: Odd ratios; CI: Confidence interval; $p^{\dagger}$ : value of $p$ from chi square analysis. 


\section{Discussion}

The type of sport and recreational activities performed most by the adult population of Seville in PS was that of walking (for $40 \%$ ). Although few studies have analysed the types of sport and recreational activities as a function of the different spaces or facilities in which they are performed, there is similarity with other studies where walking also appears as the most frequent type of activity. These findings coincide with other studies such as ODA [13], in this case with a rate of $68.8 \%$ and those presented in the survey on sports habits in Spain [12] where it accounted for $70.6 \%$, while in the region of Andalusia the figure was $67.5 \%$. However, we should bear in mind that this study only analysed data from those people who did an activity with the intention of doing sport, without considering those who walk or cycle (or any other activity) for mobility. This could explain why the rates for walking at a regional or national level are higher than the ones we found in this study.

There would seem to be a strong argument from a municipal point of view for revitalizing spaces and urban routes to promote walking as a sport and recreational activities. Public urban routes which are suitable for walking could feature the same type of information given for hill-walking, such as: signposting of routes, distances, levels of difficulty and other details (steps, kilometres, calorie expenditure, etc.).

In the previously mentioned studies [12,13], second place was for running and cycling [23] and this study on PS had similar findings, although the rates for cycling and running have increased in recent years. This could be explained by the fact that Seville is so well suited to cycling due to the excellent climate with agreeable temperatures throughout the year, the flat terrain and the implementation of regional plans encouraging cycling, such as the current Plan Andaluz de la bicicleta [Andalusian Bike Plan] 2014-2020 [24] and the increase in the kilometres of bike lanes from $77 \mathrm{~km}$ in 2007, to $120 \mathrm{~km}$ in 2010 [25] and reaching almost $180 \mathrm{~km}$ in 2017 [26]. However, towns should continue to extend and improve paths and bike-lanes, improving their safety and incorporating refreshment points and public information and first-aid points.

In contrast, results in this paper show that activities that could be undertaken in urban PS in Seville, such as Tai chi-yoga, roller-skating or even rowing-canoeing, have very low levels of practice, the first at $2 \%$ and the other types under $1 \%$. In regional and national surveys on sport and recreational activities habits [12,13], results about the practice of these activities are not even included due to the insignificant number of people who do them. Furthermore, activities such as Tai chi-yoga can be done at home and are normally offered by gyms and sports facilities, so that people doing these types of activities can do them elsewhere [27]. But this does not mean that this type of activity should be ignored. Indeed, one way of encouraging these activities in PS would be to include these spaces in municipal sport programs, enabling sports activities funded by the town hall to be carried out there. This would be possible due to the city's climate and temperature, which normally allow people to do sport and recreational activities outdoors throughout the year. Sport and recreational activities classes could be organized for the adult population in parks, squares and other settings not used by the population group such as the river. Free sessions to try out new activities could be organized to promote them.

Studies analysing the relations between different variables associated with the use of PS for sports and recreational activities are scarce. However, the study by Tejero-González [17] found that the activity of walking was associated with the variables of gender, age, socioeconomic status and level of studies. Similarly, other studies [14,26,28] have found relations between the use of PS with socio-demographic variables and profiles of practice. However, this study found that doing sport and recreational activities in PS may be conditioned by the type of activity, the person's gender and age and the frequency, duration, days of the week and time of the year in which the activity is performed.

In this paper, gender can help to explain the use of PS given the correlations and associations established, in line with most studies indicating that men use PS more to do sport and recreational activities $[12,14,16,18]$, although the percentages of use for women are similar. However, one study [29] 
conducted with university students indicated that that first option for women is to use public spaces, while for men it is their second option after sports centres.

We also found that age is a variable that is related to the use of PS, along the lines of the work by Chacón et al. [14] which indicated that as age increased so did the use of these spaces and vice versa. Similarly, the results of the Eurobarometer [11] showed that participation in sport and recreational activities in a park or outdoors is less common amongst young people aged 15-24 (30\%); however, this increases in older age groups, reaching $38-43 \%$. Spanish national data [12] indicates an increase in the use of PS up to the age interval of $45-54$ where it reaches $73 \%$ and then a slight decrease in people over $55(61 \%)$.

The duration of the sporting activity and the use of PS had an inverse correlation, although the duration with the highest percentage in this study was more than one hour, a figure which is not easily comparable with the results from other works analysing this variable in terms of number of days per week and which conclude that the mean is $44.4 \mathrm{~min}$ per day for the Spanish population [12] or $2.29 \mathrm{~h}$ per week [24].

The frequency of sport and recreational activities in the adult population of Seville, where more than twice a week was most frequent (66.2\%), differs from the data of the Eurobarometer [11] which show that people who do exercise in parks or outdoors do so 5 times or more per week (50\%), which is more than those who use other types of sport and recreational activities facilities. This is a similar figure to the data obtained by the ODA [13] for the activity of walking, where $50.8 \%$ did this every or nearly every day and $27 \%$ did so 2 or 3 times a week. However, the MECYD study [12] found that the most used frequency was once a week (46.2\%).

In turn, $37.7 \%$ of the adult population of Seville did sport and recreational activities on any day of the week, indifferent to whether it was a weekday or weekend. The descriptive results were similar to those obtained by the MECYD [12], in which week days were used by $40.7 \%$, while $41.6 \%$ were indifferent about the day. On the same lines, Andalusians [13] performed activities every or nearly every day $(54.8 \%)$. In all the papers analysed, only a minority did sport and recreational activities exclusively at the weekend.

In terms of the correlations and associations between the time of the year that people do sport and recreational activities in PS, we found that $82.7 \%$ made no distinction between periods of vacation or non-vacation. This is a higher percentage than that obtained by the MECYD [12] for the Spanish population as a whole and the ODA [13] among the population from the province of Seville (66.1\% and $68.3 \%$ respectively), although this lack of distinction regarding the time of year, was also the most common. The results coincided in finding that the vacation period was the period of the year used least to do sport and recreational activities exclusively with percentages $\leq 10 \%$. We know of only one study which found that the periods used most were the summer and the autumn [18].

\section{Conclusions}

In relation to the objectives of this study, we can conclude that the characteristics of sport and recreational activities associated with and determining the use of PS by the adult population of Seville were high frequency, duration and regularity and on any day of the week or at any time of the year. Similarly, we confirmed the sociodemographic variables determining the use of PS as age and gender.

This information may be important when it comes to planning the design and promotion of public spaces for sports activities. Sports criteria should be included in urban planning, local regulations and planning codes as part of the local authority's role in facilitating and encouraging people to do sport and recreational activities. In each neighbourhood there should be at least one suitable and accessible place where people can do sport and recreational activities easily and safely.

Apart from continuing to promote activities such as walking, running or cycling, attempts could also be made to encourage the use of public spaces for other less popular activities such as Tai chi-yoga, roller-skating or even rowing-canoeing, given the availability of one the best training tracks in Spain for water sports and water recreational activities: the river Guadalquivir. Similarly, policies could be 
introduced to encourage younger people, particularly men, to use these spaces and try to increase the overall frequency that people do their activity, beyond the current rate of twice a week.

It is important to continue raising the awareness of the population about the beneficial effects of sport and recreational activities on health and drive home the message that you do not need to be rich to do sport. It is there for everyone and public spaces provide an ideal setting.

However, as we stated above, there is little in the bibliography about the use of PS for doing sport and recreational activities and in many cases, data cannot be compared directly because of the use of different units of measurement (for example, for the duration or frequency of the activities). For that reason, any comparisons should be treated with caution, while it is crucial to continue analysing the factors which influence the practice of sport and recreational activities in public spaces. The data from this study should be taken into consideration so that public policies may steadily enable people to appropriate these spaces and, through the use they make of them, configure a more active, healthy and sustainable lifestyle for themselves.

Author Contributions: F.C.-B., study conception and design; A.M.-M. and C.C.-V., acquisition of data; F.C.-B. and J.A.C.-P., analysis and interpretation of data; F.C.-B. and C.C.-V., drafting of manuscript; J.A.C.-P. and A.M.-M., critical revision. All authors read and approved the final manuscript.

Funding: The authors received no specific funding for this work.

Conflicts of Interest: The authors declare no conflict of interest.

\section{References}

1. Urbina Casasola, Y. Espacio público urbano como catalizador de actividad física y bienestar psicológico. Rev. Wímblu 2014, 9, 67-81. [CrossRef]

2. Castells, M. La era de la Información. Economía, Sociedad y Cultura; Alianza Editorial, Ed.; La Sociedad: Madrid, Spain, 1997.

3. Bourdieu, P. Meditaciones Pascalianas; Editorial Anagrama: Barcelona, Spain, 1999.

4. Cardona Rendon, B.M. Espacios de ciudad y estilos de vida El espacio público y sus apropiaciones. Rev. Educ. Física Deporte 2008, 27, 39-47. Available online: http:/ / aprendeenlinea.udea.edu.co/revistas/index.php/ educacionfisicaydeporte/article/view/2246 (accessed on 18 February 2018).

5. Wanz, Z.; Olson, E. Present status, potential and strategies of physical activity in China. Int. Rev. Sociol. Sport 1997, 32, 69-85.

6. Hernández-Aparicio, E. Estudio De Los Circuitos Biosaludables Para La Tercera Edad En España. A Study of Geriatric Parks for Erderly People in Spain. Rev. Int. Med. Cienc. Act. Física Deporte 2008, 9, 25-38.

7. Sarmiento, O.; Torres, A. La ciclovía-recreativa: Un programa masivo de recreación con potencial en salud pública. J. Phys. Act. Health 2010, 7, 163-180. [CrossRef]

8. Magrinyà, F.; Mayorga, M.Y. Diseñar la ciudad para el deporte en los espacios públicos. Apunts Educ. Física Deportes 2008, 1, 102-113.

9. Barnett, D.W.; Barnett, A.; Nathan, A.; Van Cauwenberg, J.; Cerin, E. Built environmental correlates of older adults' total physical activity and walking: A systematic review and meta-analysis. Int. J. Behav. Nutr. Phys. Act. 2017, 14, 103. [CrossRef] [PubMed]

10. Puig, N.; Maza, G. El deporte en los espacios públicos urbanos. Reflexiones introductorias. Apunts Educ. Física Deportes 2008, 91, 3-8.

11. European Commission. Special eurobarometer 472 report sport and physical activity fieldwork december 2017 publication survey requested by the european commission. In Special Eurobarometer 472 Report; European Commission: Brussels, Belgium, 2018.

12. Ministerio de Educación Cultura y Deporte. Encuesta de Hábitos Deportivos en España 2015; Ministerio de Educación Cultura y Deporte: Madrid, Spain, 2015.

13. Observatorio del Deporte Andaluz. Hábitos y Actitudes de la Población Andaluza Ante el Deporte 2012 ODA Página 1 de 104; Observatorio del Deporte Andaluz: Andaluz, Spain, 2012.

14. Chacón-Borrego, F.; Corral-Pernía, J.A.; Ubago-Jiménez, J.L. Uso de espacios públicos para la práctica de actividad física. Influencia de variables sociodemográficas en personas adultas. J. Sport. Econ. Manag. 2017, 7, 120-129. 
15. Martínez del Castillo, J.; González, M.D.; Jiménez-Beatty, J.E.; Graupera, J.L.; Martín, M.; Campos, A.; del Hierro, D. Los hábitos de actividad física de las mujeres mayores en España. RICYDE Rev. Int. Cienc. Deporte 2009, 5, 81-93. [CrossRef]

16. Vilanova, A.; Soler, S. Las mujeres, el deporte y los espacios públicos: Ausencias y protagonismos. Apunts Educ. Física y Deportes 2008, 1, 29-34.

17. Tejero-González, C.M. Práctica deportiva y práctica de paseo. Diferencias y similitudes sociodemográficas en España. Rev. Española Educ. Física y Deportes 2017, 418, 491-498.

18. Chow, B.C.; McKenzie, T.L.; Sit, C.H.P. Public parks in Hong Kong: Characteristics of physical activity areas and their users. Int. J. Environ. Res. Public Health 2016, 13, 639. [CrossRef] [PubMed]

19. Zainol, R.; Au-Yong, C.P. What brings youth to recreational parks? Plan. Malays. J. 2016, 14, 67-80. [CrossRef]

20. Arribas, S.; Gil de Montes, L.; Arruza, J. Práctica de Actividad Física y Deporte en la Población Adulta de Guipúzcoa: Datos Comparativos; Universidad del País Vasco: San Sebastian, Spain, 2006; Available online: http:/ / www.kirolbegi.net/docs/slides/PAFYD_Estudio_comparativo_poblacion_adulta_2006.pdf (accessed on 20 April 2018).

21. UK Sport; Sport England; Comitato Olimpico Nazionale Italiano. Sport Participation in Europe; COMPASS: London, UK, 1999.

22. Pulver, A.E.; Bartko, J.J.; Carpenter, W.T. The power of analysis: statistical perspectives: Part 1. Psychiatry Res. 1988, 23, 301-309. [CrossRef]

23. Barripedro, M.; Martínez del Castillo, J.; Jiménez, J.; Rivero, A. Diferencias de género en los hábitos de actividad física de la población adulta en la Comunidad de Madrid. Int. J. Sport Sci. 2014, 10, 319-335. [CrossRef]

24. Junta de Andalucía. Plan Andaluz de la Bicicleta. PAB 2014-2020; Junta de Andalucía: Seville, Spain, 2014.

25. Marqués, R.; Hernández, V.; Calvo, M.; García-Cebrián, J. Velo-City Global 2012: A Successful Experience of Promotion of Urban Cycling in the South of Europe. Available online: https://issuu.com/ vicentehernandezherrador/docs/presentacion_velocity/18 (accessed on 1 May 2018).

26. Ybarra, P. ABC de Sevilla; Sevilla, Spain, 2017; Available online: https://sevilla.abc.es/sevilla/sevi-sevillaciudad-180-kilometros-carril-bici-201704182331_noticia.html (accessed on 1 May 2018).

27. Ayala, S.G.; Wallson, K.; Birdee, G. Characteristics of yoga practice and predictors of practice frequency. Int. J. Yoga Ther. 2018, 28, 1-5. [CrossRef] [PubMed]

28. Chacón Cuberos, R.; Borrego, F.C.; Ortega, F.Z.; Zagalaz, J.C.; Luisa, M.; Sánchez, Z.; José, J.; Mira, C. Characterization of motivation and type of physical-sport practice in adults through COMPASS profiles. Área Educ. Física y Deporte 2018, 13, 161-173. [CrossRef]

29. Castañeda-Vázquez, C.; Zagalaz-Sánchez, M.L.; Chacón-Borrego, F.; Cachón-Zagalaz, J.; Romero-Granados, S. Características de la práctica deportiva en función del género. Estudiantes de la Facultad de Ciencias de la Educación: Universidad de Sevilla. Retos Nuevas Tendencias Educ. Física Deporte y Recreación 2014, 22, 63-67. 